\title{
Overexpression of CDCA8 promotes the malignant progression of cutaneous melanoma and leads to poor prognosis
}

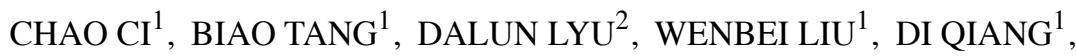 \\ XIANG JI ${ }^{1}$, XIAMIN QIU ${ }^{1}$, LEI CHEN ${ }^{2}$ and WEI DING $^{2}$ \\ Departments of ${ }^{1}$ Dermatology, and ${ }^{2}$ Burn and Plastic Surgery, \\ First Affiliated Hospital of Wannan Medical College, Wuhu, Anhui 241001, P.R. China
}

Received April 12, 2018; Accepted October 30, 2018

DOI: $10.3892 /$ ijmm.2018.3985

\begin{abstract}
Cutaneous melanoma is very aggressive and results in high mortality rates for cancer patients. Determining molecular targets is important for developing novel therapies for cutaneous melanoma. Cell division cycle associated 8 (CDCA8) is a putative oncogene that is upregulated in multiple types of cancer. The present study aimed to examine the role of CDCA8 in cutaneous melanoma, with a focus on the association of its expression to prognosis and metastasis. First, the mRNA expression of CDCA8 in cutaneous melanoma tissues was investigated using the ONCOMINE and Gene Expression Omnibus (GEO) databases. Furthermore, the relationship between the expression of CDCA8 and cutaneous melanoma patient survival was analyzed using a Kaplan-Meier plot and Log Rank test. In addition, the effects of CDCA8 on proliferation, migration and invasion of cutaneous melanoma cell lines were investigated using reverse transcription-quantitative polymerase chain reaction (RT-qPCR), Cell Counting kit-8, colony formation assay, wound healing and Matrigel assay. Finally, the expression levels of key proteins related to the Rho-associated coiled-coil-containing protein kinase (ROCK) signaling pathway were measured by western blot assay. The results demonstrated that CDCA8 was overexpressed in cutaneous melanoma tissues and cells lines compared with normal tissues, and high expression of CDCA8 was significantly associated with poorer prognosis in patients with cutaneous melanoma. In in vitro experiments, CDCA8 knockdown inhibited A375 and MV3 cell proliferation, migration and invasion. In addition, CDCA 8 knockdown reduced the phosphorylation levels of ROCK1 and myosin light chain, two downstream effector proteins of the ROCK pathway. In summary, the present findings suggested that CDCA8 may
\end{abstract}

Correspondence to: Dr Dalun Lyu, Department of Burn and Plastic Surgery, First Affiliated Hospital of Wannan Medical College, Zheshanxi Road, Wuhu, Anhui 241001, P.R. China E-mail: lvdalun0776@163.com

Key words: cell division cycle associated 8, cutaneous melanoma, prognosis, target gene, proliferation, Rho-associated coiled-coil-containing protein kinase be a promising therapeutic target for the treatment of cutaneous melanoma.

\section{Introduction}

Cutaneous melanoma is transformed from melanocytes, and the predominant cause of melanoma is believed to be long-term UV irradiation (1). Melanoma has a highly invasive nature; even a primary tumor with a diameter of 2.5-4 $\mathrm{mm}$ can metastasize to multiple organs in the whole body, leading to a very poor prognosis $(2,3)$. In 2014 , there were $>76,000$ new cases of melanoma in the United States and $>9,000$ patients succumbed to melanoma (4). Sadly, at present, the 5-year overall survival (OS) rate for patients with stage IV melanoma is $<15 \%(5,6)$ Furthermore, patients suffering from metastatic melanoma have a poor prognosis $(1,3)$. Thus, identifying novel biomarkers related to the prognosis and progression of melanoma may improve the treatment and outcomes for patients with melanoma.

The human cell division cycle associated 8 (CDCA8) protein is an integral part of the vertebrate chromosomal passenger complex (CPC) (7). The CPC consists of at least four proteins: Aurora B, inner centromere protein (INCENP), survivin, and CDCA8, overexpression of which is associated with tumorigenesis of human cancers $(8,9)$. CDCA8 is a putative oncogene that is upregulated in multiple types of cancer and is necessary for the survival and malignant nature of various cancer cells (10). Its overexpression is involved in the progression of lung cancer and breast cancer (11), and can result in poor prognosis of gastric cancer and lung cancer (12). Thus, CDCA8 is considered to be a promising target for the development of novel therapeutics and diagnostics. Despite these previous studies, the role of CDCA8 on cutaneous melanoma remains unexplored.

Rho-associated coiled-coil-containing protein kinase (ROCK) is a serine threonine kinase modulating several critical cellular processes, including actin cytoskeleton organization, apoptosis, reactive oxygen species formation, cell migration and adhesion (13-15). In mammalians, two highly homologous isoforms, ROCK1 and ROCK2 has been identified. ROCK has several phosphorylation substrates, including myosin light chain (MLC), myosin light chain phosphatase (MLCP), and LIM kinase (LIMK) (16), and recent studies 
have identified ROCK as a promising candidate for the therapy of highly metastatic cancer (17).

The present study aimed to investigate the role of CDCA8 in cutaneous melanoma and its effect on the ROCK signaling pathway. First, the mRNA expression of CDCA8 in cutaneous melanoma tissues and the association between CDCA8 expression and cutaneous melanoma patient survival were examined, using the ONCOMINE and Gene Expression Omnibus (GEO) databases. Second, the effects and functional mechanism of CDCA8 on cutaneous melanoma cell lines were investigated in vitro.

\section{Methods and materials}

Database analysis. The data of CDCA8 expression in cutaneous melanoma were downloaded from the ONCOMINE (http://www.oncomine.org) database, which contained 45 cutaneous melanoma samples and 7 normal samples. In addition, CDCA8 expression data (GSE8401) for melanoma metastases were downloaded from the public GEO (https://www.ncbi. nlm.nih.gov/geo/) database, which contained 31 primary melanoma tumor samples and 52 metastatic melanoma tumor samples.

The relationship of CDCA8 expression with clinical features in cutaneous melanoma patients was analyzed using data downloaded from The Cancer Genome Atlas (TCGA; https://cancergenome.nih.gov/) database. Based on these data, a statistical analysis of the effect of CDCA8 on the prognosis of cutaneous melanoma was performed.

Cell culture. The human cutaneous melanoma cell lines A375 and MV3, and the normal human cells Hacat were purchased from the Type Culture Collection of the Chinese Academy of Sciences (Shanghai, China). Cells were routinely cultured in RPMI-1640 culture medium (Thermo Fisher Scientific, Inc., Waltham, MA, USA) at $37^{\circ} \mathrm{C}$ in a $5 \% \mathrm{CO}_{2}$ atmosphere, supplemented with $100 \mathrm{U} / \mathrm{ml}$ penicillin, $0.1 \mathrm{mg} / \mathrm{ml}$ streptomycin (both from Sigma-Aldrich; Merck KGaA, Darmstadt, Germany) and a fetal bovine serum (Gibco; Thermo Fisher Scientific, Inc.) concentration of $10 \%$. The cells were washed 3 times with PBS and digested with trypsin following growth to the logarithmic phase. A single cell suspension was then seeded into six-well plates for following experiments.

Cell transfection. When cell density in the six-well plates reached $\sim 80 \%$, according to the manufacturer's instructions, the cells were transfected with small interfering (si)RNA targeting CDCA8 (si-CDCA8, 5'-GUGGAAAUACGAAUCAAGC-3'), or non-specific control si-RNA (si-con; 5'-UUCUCCGAA CGUGUCACGU-3') using Lipofectamine 2000 transfection reagent (Invitrogen; Thermo Fisher Scientific, Inc.) for $24 \mathrm{~h}$. Afterwards, the effect of the siRNA transfection was verified by reverse transcription-quantitative polymerase chain reaction (RT-qPCR), and the cells were used for subsequent experiments.

$R T$-qPCR assay. Following transfection for $24 \mathrm{~h}$, total RNA was extracted from cells by $1.0 \mathrm{ml}$ TRIzol (Invitrogen; Thermo Fisher Scientific, Inc.). Total RNA was synthesized into cDNA with the reverse transcriptase M-MLV kit (Takara Biotechnology Co. Ltd., Dalian, China). The expression levels of CDCA8 were detected by qPCR using the SYBR Premix Ex Taq kit (Applied Biosystems, Foster City; Thermo Fisher Scientific, Inc.). The primers were: GAPDH forward, 5'-GGAGCGAGATCCCTC CAAAAT-3' and reverse, 5'-GGCTGTTGTCATACTTCT CATGG-3'; and CDCA8 forward, 5'-GTTCCAAGGAGAAGC CCACA-3' and reverse, 5'-CCGGTCCACATTCTCTGGAA-3'. GAPDH was used as an internal control. The specific thermocycling conditions were as follows: $5 \mathrm{~min}$ at $95^{\circ} \mathrm{C}$, followed by 40 cycles of $95^{\circ} \mathrm{C}$ for $30 \mathrm{sec}$ and $60^{\circ} \mathrm{C}$ for $45 \mathrm{sec}$, and a final step of $72^{\circ} \mathrm{C}$ for $30 \mathrm{~min}$. The relative quantification of CDCA8 expression was determined by the $2^{-\Delta \Delta \mathrm{Cq}}$ method (18) and each sample was repeated three times independently.

Cell proliferation assay. At $24 \mathrm{~h}$ post-transfection, cells were counted and $100 \mu \mathrm{l}$ cell suspensions (1,000 cells/well) were seeded into 96-well plates. According to the manufacturer's introductions, the viability of A375 and MV3 cells was detected every $24 \mathrm{~h}$ (at 24, 48, 72 and $96 \mathrm{~h}$ ) using the Cell Counting kit-8 assay (CCK-8; Beijing Solarbio Science \& Technology Co., Ltd., Beijing, China), after $10 \mu \mathrm{l}$ CCK-8 reagent was added in each well. A proliferation curve was plotted based on optical density (OD) values measured at $450 \mathrm{~nm}$ by a microplate reader (Bio-Rad Laboratories, Inc., Hercules, CA, USA). Every sample was assayed three times.

Colony formation assay. Cell suspensions (400 cells/plate) were seeded into $60 \mathrm{~mm}$ plates containing $5 \mathrm{ml}$ culture medium at $37^{\circ} \mathrm{C}$, following transfection for $24 \mathrm{~h}$. After 2 weeks, visible clones could be observed in the culture plates. Subsequently, colonies were fixed and stained for $30 \mathrm{~min}$, following washing 2 times with PBS. The number of colonies in the two groups were counted and compared under a microscope in 5 random optical fields. Each sample was repeated in triplicate.

Matrigel and wound healing assay. Matrigel and the wound healing assay were used to detect cell invasion and migration, respectively. For cell invasion, $100 \mu \mathrm{l}$ Matrigel (BD Biosciences, Franklin Lakes, NJ, USA; serum-free medium diluted 1:6) was added to the upper chamber of a 24 -well plate Transwell chamber and then placed in a $37^{\circ} \mathrm{C} 5 \% \mathrm{CO}_{2}$ incubator for 4-6 $\mathrm{h}$ to form a gel. Subsequently, $100 \mu \mathrm{l}$ transfected cell suspension $\left(1 \times 10^{5}\right)$ was added in the upper chamber, while $500 \mu$ l complete medium was added into the bottom chamber. Following overnight culture so that the cells invade to the lower surface of the filter, cells were washed and fixed with $4 \%$ paraformaldehyde for $30 \mathrm{~min}$. Finally, invaded cells were stained with $0.1 \%$ crystal violet for $20 \mathrm{~min}$ and 5 visual fields were selected randomly using a BX51 inverted microscope (Olympus Corporation, Tokyo, Japan) at magnification, x100.

For the wound healing assay, cells were cultured in RPMI-1640 medium in six-well plates $\left(5 \times 10^{5}\right.$ cells $\left./ \mathrm{ml}\right)$ for $24 \mathrm{~h}$, then a wound was made in each plate with a $100 \mu \mathrm{l}$ plastic pipette tip. After being washed three times with PBS, the cells were cultured for another $24 \mathrm{~h}$. The wound width was then observed in each well using an Olympus BX51 microscope (Olympus Corporation) at magnification, x200 in five random fields. Each sample was performed in triplicate.

Western blot analysis. Following transfection for $24 \mathrm{~h}$, total proteins were extracted from the cells with the Radio 

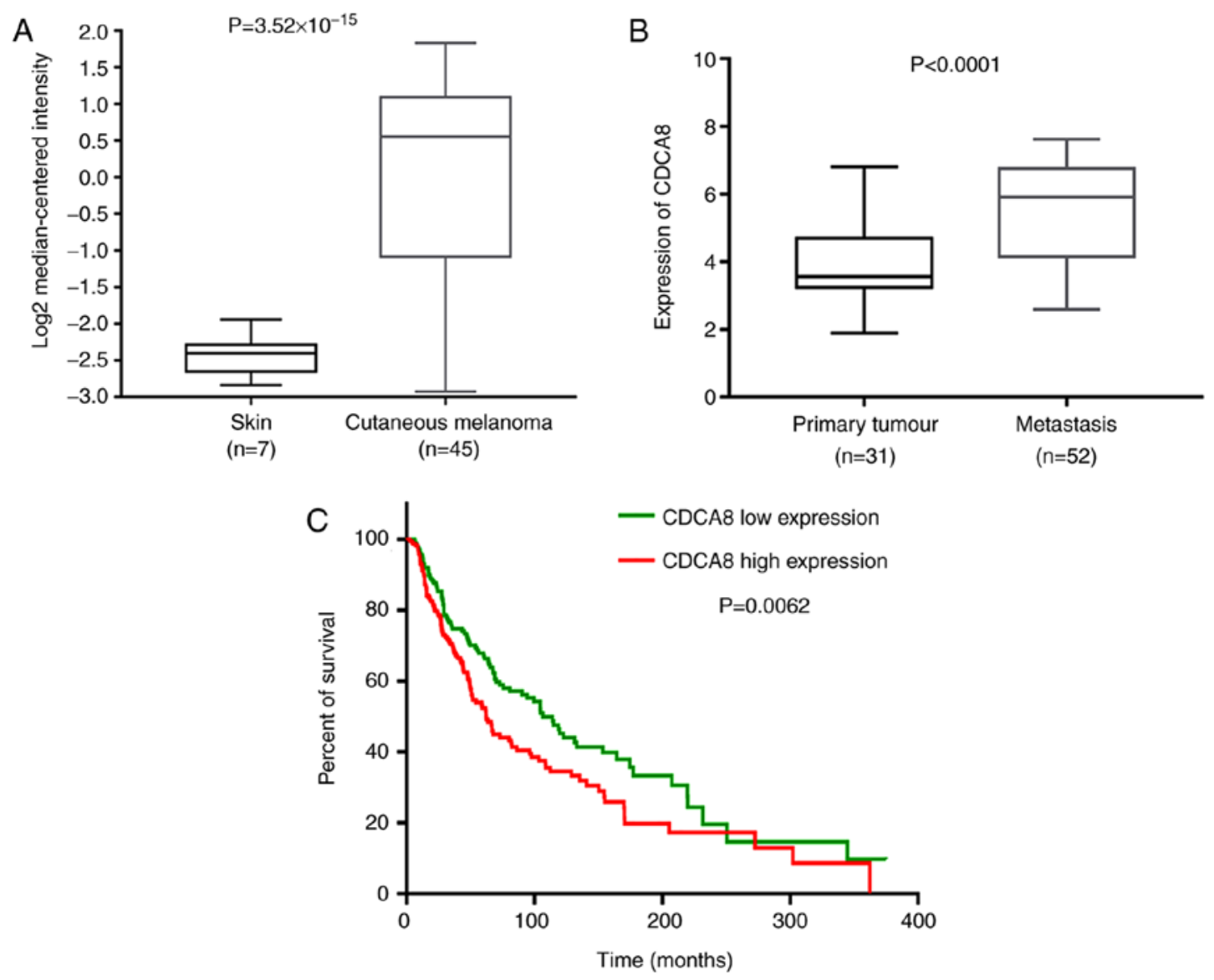

Figure 1. Expression of CDCA8 in cutaneous melanoma tissues based on ONCOMINE and GEO databases. (A) Expression levels of CDCA8 in cutaneous melanoma tissues $(\mathrm{n}=45)$ and normal skin $(\mathrm{n}=7)$ from the ONCOMINE database were analyzed. (B) Expression levels of CDCA8 in metastatic tumors $(n=52)$ and primary tumors $(n=31)$ from the GEO database were analyzed. (C) Survival analysis for patients with low or high expression levels of CDCA8, by Kaplan-Meier method and Log rang test. CDCA8, cell division cycle associated 8; GEO, Gene Expression Omnibus.

Immunoprecipitation Assay (RIPA) lysis buffer (Beyotime Institute of Biotechnology, Shanghai, China). Then the protein concentrations were quantified with a BCA Protein Assay kit (Beyotime Institute of Biotechnology). Total protein samples $(20 \mu \mathrm{g} /$ lane $)$ were separated by SDS-PAGE in a $10 \%$ polyacrylamide sequencing gel and transferred onto a polyvinylidene fluoride (PVDF) membrane. Following blocking with $5 \%$ non-fat dry milk for $1 \mathrm{~h}$, the membranes were incubated with primary antibodies overnight at $4^{\circ} \mathrm{C}$. After washing for 3-5 min, the membranes were incubated with secondary antibodies at room temperature for $1 \mathrm{~h}$. The antibodies were as follows: ROCK1 Rabbit Polyclonal antibody (cat. no. 21850-1-AP; 1:1,000 dilution), $\beta$-Actin Rabbit Polyclonal antibody (cat. no. 20536-1-AP; 1:1,000 dilution), MLC 2 Rabbit Polyclonal antibody (cat. no. 55462-1-AP; 1:2,000 dilution) and secondary horseradish peroxidase-labelled goat anti-rabbit antibody (cat. no. 10545-2-AP; 1:5,000 dilution), Rabbit anti-human tubulin (cat. no. 10068-1-AP; 1:5,000 dilution; all ProteinTech Group, Inc., Chicago, IL, USA) was used as the internal control and the relative expression of the target protein was calculated relative to the tubulin expression, following detection with an electro-chemiluminescence imaging analysis system (Thermo Fisher Scientific, Inc.). The bands were scanned and analyzed with the Quantity One software (Bio-Rad Laboratories, Inc.).
Statistical analysis. The Kaplan-Meier's estimator and the Log rank test were used to detect the prognostic value of CDCA8 expression. Comparisons between two groups were performed with the Student's t-test, while comparisons between multiple groups were performed with one-way analysis of variance. Comparison between the groups was made by a Student-Newman-Keuls test. All statistical analyses were performed with SPSS 22.0 (IBM Corp., Armonk, NY, USA) software. Data were presented as mean \pm standard deviation. $\mathrm{P}<0.05$ was considered to indicate a statistically significant difference.

\section{Results}

CDCA8 is upregulated in cutaneous melanoma tissues. Firstly, based on the ONCOMINE and GEO data, CDCA8 expression levels were demonstrated to be significantly increased in cutaneous melanoma tissues compared with normal skin tissues (Fig. 1A). In addition, CDCA8 levels in metastatic melanoma tumors were significantly higher compared with primary melanoma tumors (Fig. 1B).

Correlation of CDCA8 expression and clinical characteristics of patients with cutaneous melanoma. In order to further explore the impact of CDCA8 on cutaneous melanoma progression, RNA-Sequencing data of CDCA8 expression 
from TCGA database were downloaded, and the correlation was analyzed using Perl language package and Chi-square test. As presented in Table I, the expression levels of CDCA8 were significantly associated with lymph node metastasis in cutaneous melanoma patients $(\mathrm{P}=0.039)$. By contrast, age, sex, clinical-stage, primary tumor and metastasis stage were not relevant to CDCA8 expression (all $\mathrm{P}>0.05$ ). These results indicated that CDCA 8 was associated with the progression of cutaneous melanoma.

High CDCA8 expression is associated with poor prognosis in cutaneous melanoma patients. Next, the correlation between the prognosis of cutaneous melanoma patients and CDCA8 expression levels was explored using Kaplan-Meier analysis and Log-rank test. As illustrated in Fig. 1C, the survival rates of the CDCA8 high expression group and the low expression group were significantly different $(\mathrm{P}=0.0062)$. The overall survival time of patients with high CDCA8 expression was significantly shorter, suggesting that CDCA8 expression might be a prognostic marker in cutaneous melanoma patients.

In order to further confirm these results, cox proportional hazards analysis was performed (Table II). Significant univariate associations of survival were observed for CDCA8 expression, clinical stage, pathologic-T, pathologic-N stage and age (all $\mathrm{P}<0.01$; Table II). Multivariate analysis further identified two of these factors to be significant negative predictors of survival: CDCA8 expression [hazard ratio $(\mathrm{HR})=1.615$, $\mathrm{P}=0.003)$ ] and pathologic- $\mathrm{T}$ stage $(\mathrm{HR}=1.923, \mathrm{P}=0.000)$. These results demonstrated that CDCA8 was an independent predictor for prognosis of cutaneous melanoma patients.

CDCA8 is overexpressed in cutaneous melanoma cells. To characterize the prognosis-associated CDCA8 activity in vitro, the expression levels of CDCA8 were examined in cutaneous melanoma cells A375 and MV3, and in the normal Hacat cells, by RT-qPCR analysis. As illustrated in Fig. 2A, CDCA8 expression was significantly increased in A375 and MV3 cells compared with Hacat cells (both $\mathrm{P}<0.01$ ). These results suggested that CDCA8 was upregulated in cutaneous melanoma cells.

CDCA8 knockdown in A375 and MV3 cells. Subsequently, a knockout vector carrying siRNA targeting CDCA8 (si-CDCA8) was transfected into A375 and MV3 cells. A non-targeting siRNA sequence (si-con) was used as a control. Total RNA and total protein was extracted from the cells at $24 \mathrm{~h}$ post-transfection and examined by RT-qPCR and western blot analysis, respectively. The results demonstrated that si-CDCA8 could significantly reduce the mRNA and protein expression levels of CDCA8 in A375 and MV3 cells, and the knockdown efficiency was $>70 \%$ (Fig. 2B-D; all $\mathrm{P}<0.01$ ).

CDCA8 knockdown results in decreased proliferation in cutaneous melanoma cells. The function of CDCA8 was explored next in cutaneous melanoma cells. Firstly, cell proliferation activity was examined following CDCA8 knockdown in A375 and MV3 cells using CCK-8 and colony formation assays. In A375 cells, the OD value in si-CDCA8 group was significantly decreased compared with the si-con group at 72 and 96 h (Fig. 3A; P<0.01). Similar
Table I. Clinicopathological parameters of patients with cutaneous melanoma in relation to CDCA8 expression.

\begin{tabular}{|c|c|c|c|}
\hline \multirow[b]{2}{*}{ Characteristic } & \multicolumn{2}{|c|}{ Expression of CDCA8 } & \multirow[b]{2}{*}{ P-value } \\
\hline & Low & High & \\
\hline Age, years & & & 0.112 \\
\hline$<60$ & 128 & 111 & \\
\hline$\geq 60$ & 101 & 118 & \\
\hline Sex & & & 0.178 \\
\hline Female & 94 & 80 & \\
\hline Male & 135 & 149 & \\
\hline Clinical stage & & & 0.091 \\
\hline $\mathrm{I}+\mathrm{II}$ & 99 & 116 & \\
\hline III+IV & 104 & 87 & \\
\hline Pathologic-T & & & 0.849 \\
\hline $\mathrm{T} 1+\mathrm{T} 2$ & 72 & 68 & \\
\hline $\mathrm{T} 3+\mathrm{T} 4$ & 121 & 119 & \\
\hline Pathologic-M & & & 0.264 \\
\hline M0 & 200 & 209 & \\
\hline M1 & 14 & 9 & \\
\hline Pathologic-N & & & $0.039^{\mathrm{a}}$ \\
\hline No & 102 & 126 & \\
\hline N1 & 97 & 79 & \\
\hline
\end{tabular}

${ }^{\mathrm{a}} \mathrm{P}<0.05$. CDCA8, cell division cycle associated 8; T, tumor; $\mathrm{M}$, metastasis; $\mathrm{N}$, node.

results were observed in MV3 cells (Fig. 3B; $\mathrm{P}<0.01$ ). In addition, the colony formation rate of cells treated with si-CDCA8 was significantly decreased compared with the control cells, in both A375 and MV3 cell lines (Fig. 3C and D; P<0.01). The present results demonstrated that knockdown of CDCA8 suppressed the proliferation of cutaneous melanoma cells.

CDCA8 knockdown inhibits cutaneous melanoma cell migration and invasion. Next, wound healing was performed to examine the migration speed of A375 and MV3 cells following CDCA8 knockdown. As illustrated in Fig. 4, cell migration was markedly decreased in CDCA8-silenced cells compared with the si-con group $(\mathrm{P}<0.01)$. Furthermore, the results from Matrigel invasion assay demonstrated that the number of invaded cells in the si-CDCA8 group was significantly reduced compared with the si-con group (Fig. 5; $\mathrm{P}<0.01)$. These findings indicated that CDCA8 knockdown inhibited migration and invasion in cutaneous melanoma cells.

CDCA8 knockdown inhibits the activation of ROCK signaling in cutaneous melanoma cells. Given that the ROCK signaling pathway has an important role in cancer and, particularly, in cell motility, metastasis and angiogenesis, the hypothesis that CDCA8 may regulate the ROCK pathway was examined in vitro. The western blot results demonstrated that CDCA8 knockdown in A375 and MV3 cells reduced the expression levels of ROCK1 and the 
Table II. Predictors of cutaneous melanoma-specific survival in patients.

\begin{tabular}{|c|c|c|c|c|c|c|}
\hline \multirow[b]{2}{*}{ Variable } & \multicolumn{3}{|c|}{ Univariate analysis } & \multicolumn{3}{|c|}{ Multivariate analysis } \\
\hline & P-value & $\mathrm{HR}$ & $95 \% \mathrm{CI}$ & P-value & $\mathrm{HR}$ & $95 \%$ CI \\
\hline CDCA8 expression (high/low) & $0.006^{\mathrm{a}}$ & 1.462 & $1.112-1.922$ & $0.003^{\mathrm{a}}$ & 1.615 & $1.173-2.223$ \\
\hline Clinical stage (I+II/III+IV) & $0.002^{\mathrm{a}}$ & 1.607 & $1.187-2.175$ & 0.657 & 0.795 & $0.289-2.186$ \\
\hline Pathologic-T (T1+T2/T3+T4) & $<0.001^{\mathrm{a}}$ & 1.967 & $1.429-2.707$ & $0.000^{\mathrm{a}}$ & 1.923 & $1.364-2.710$ \\
\hline Pathologic-M (M0/M1) & 0.161 & 1.617 & $0.826-3.169$ & & & \\
\hline Pathologic-N (N0/N1+N2+N3) & $<0.001^{\mathrm{a}}$ & 1.739 & $1.284-2.356$ & 0.092 & 2.395 & $0.867-6.611$ \\
\hline Age, years $(60 / \geq 60)$ & $0.001^{\mathrm{a}}$ & 1.650 & $1.244-2.189$ & 0.543 & 1.109 & $0.795-1.547$ \\
\hline Sex (female/male) & 0.240 & 1.191 & $0.890-1.596$ & & & \\
\hline
\end{tabular}

${ }^{\text {a }}<<0.05$. CI, confidence interval; HR, hazard ratio; CDCA8, cell division cycle associated 8; T, tumor; M, metastasis; N, node.

A

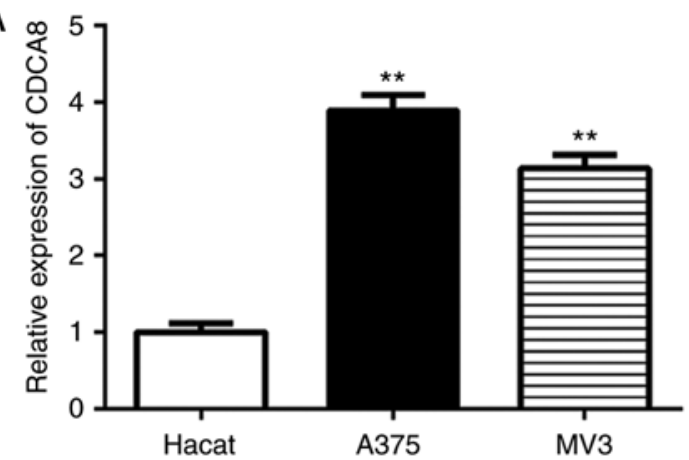

C

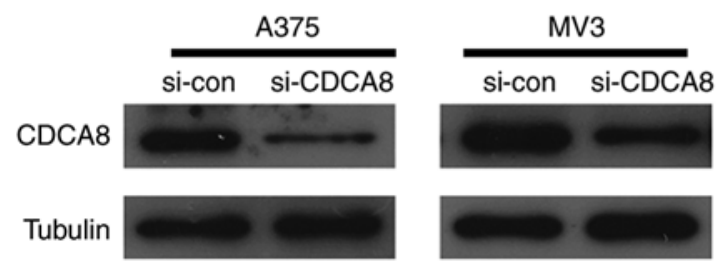

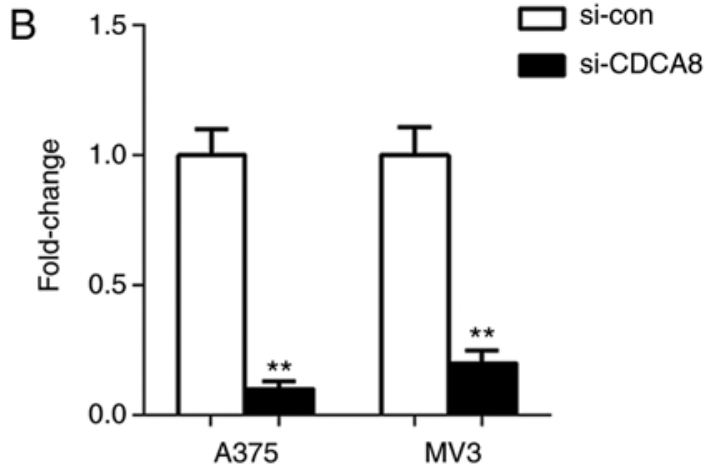

D $\left.\quad \begin{array}{ll}1.5 \\ \end{array}\right] \quad \square$ si-con

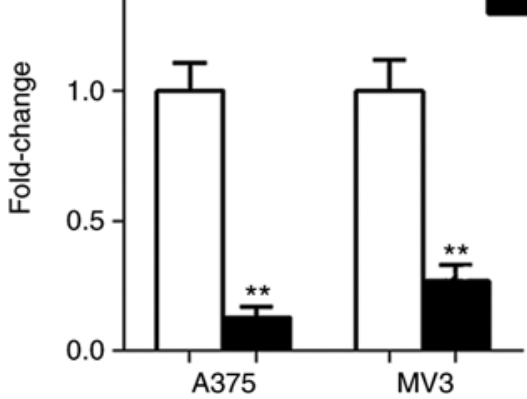

Figure 2. Expression of CDCA8 in cutaneous melanoma cell lines. (A) mRNA expression levels of CDCA8 in cutaneous melanoma cell lines A375 and MV3, and the normal cell line Hacat. ${ }^{* *} \mathrm{P}<0.01$ vs. Hacat. (B) mRNA expression levels of CDCA8 following CDCA8 knockdown by siRNA. (C) Representative blots and (D) quantification of protein expression levels of CDCA8 following CDCA8 knockdown by siRNA, as measured by western blotting. ${ }^{* *} \mathrm{P}<0.01$ vs. si-con. CDCA8, cell division cycle associated 8; si, small interfering.

phosphorylation levels of MLC, two downstream effector proteins of the ROCK pathway (Fig. 6; all $\mathrm{P}<0.01$ ). The above results indicated that the ROCK signaling pathway might be involved in cutaneous melanoma cell proliferation and invasion induced by CDCA8.

\section{Discussion}

To our knowledge, there has been no study exploring the function of CDCA8 in melanoma, including in vitro studies in cutaneous melanoma cells. In the present study, for the first time, we identified a close association between cutaneous melanoma cells and CDCA8 expression. Based on ONCOMINE and
GEO data, CDCA8 expression levels were demonstrated to be overexpressed in cutaneous melanoma tissues compared with normal tissues, and high CDCA8 expression was associated with poor prognosis in cutaneous melanoma patients. The in vitro results demonstrated that the cutaneous melanoma cell lines A375 and MV3 had increased CDCA8 expression compared with normal cells. Notably, CDCA8 knockdown inhibited cell proliferation, migration and invasion in both cutaneous melanoma cell lines. Furthermore, the regulation of CDCA8 expression and function was strongly associated with the ROCK pathway.

As a mitotic regulatory gene, the activation of CDCA8 transcription should conduce to the rapid cell growth (19). 

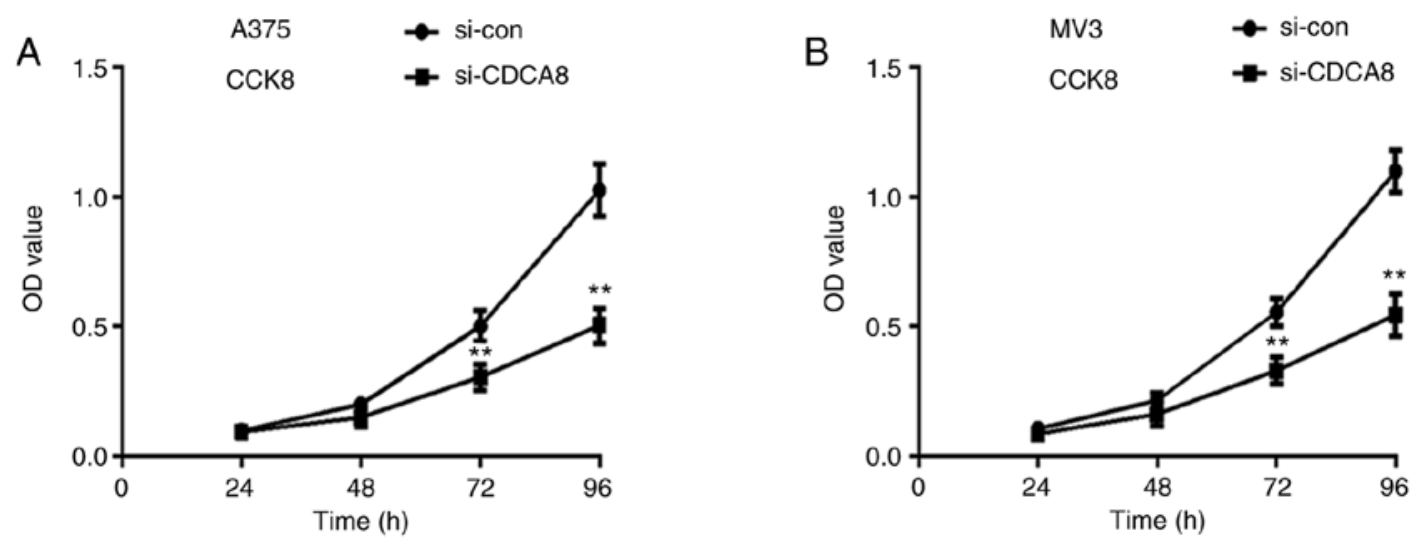

C
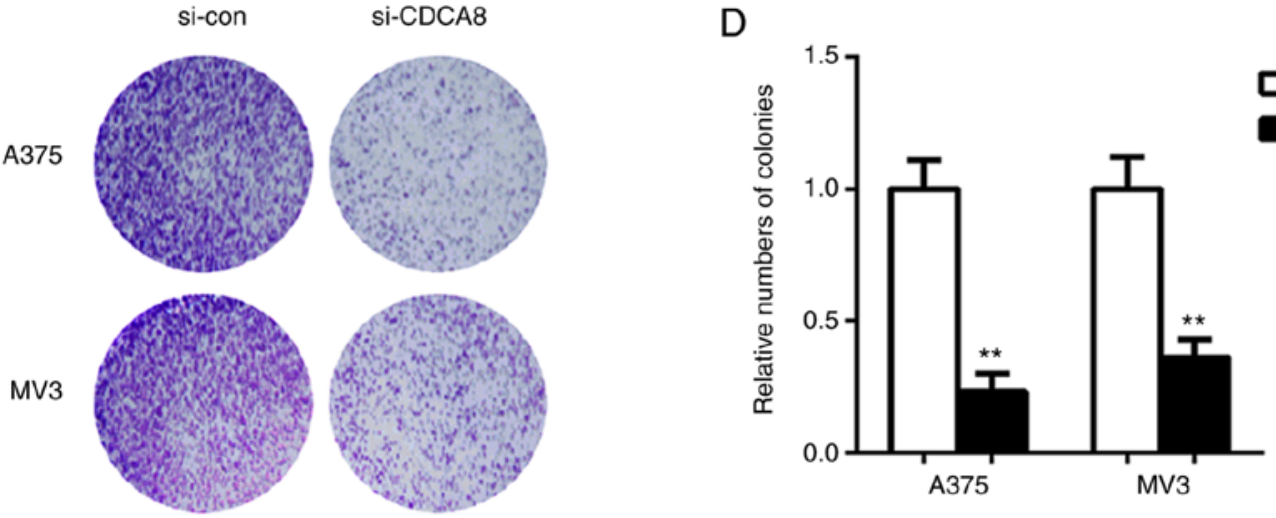

Figure 3. Effect of CDCA8 knockdown on A375 and MV3 cell proliferation. OD values resulting from the CCK-8 assay in (A) A375 and (B) MV3 cells. (C) Representative images and (D) quantification of the number of colonies resulting from the colony formation assay. ${ }^{* *} \mathrm{P}<0.01 \mathrm{vs}$. si-con. CDCA8, cell division cycle associated 8; OD, optical density; CCK-8, cell counting kit-8; si, small interfering.

A

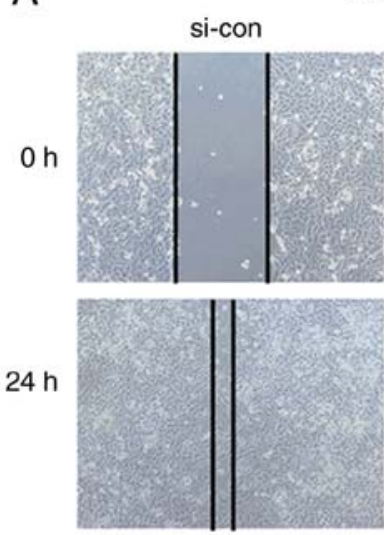

C

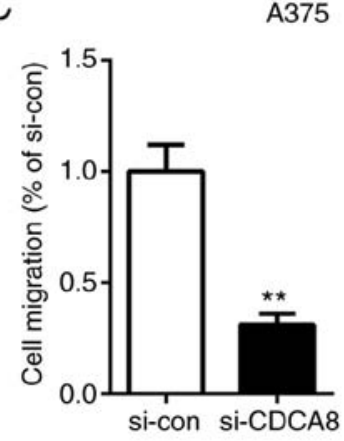

A375
B
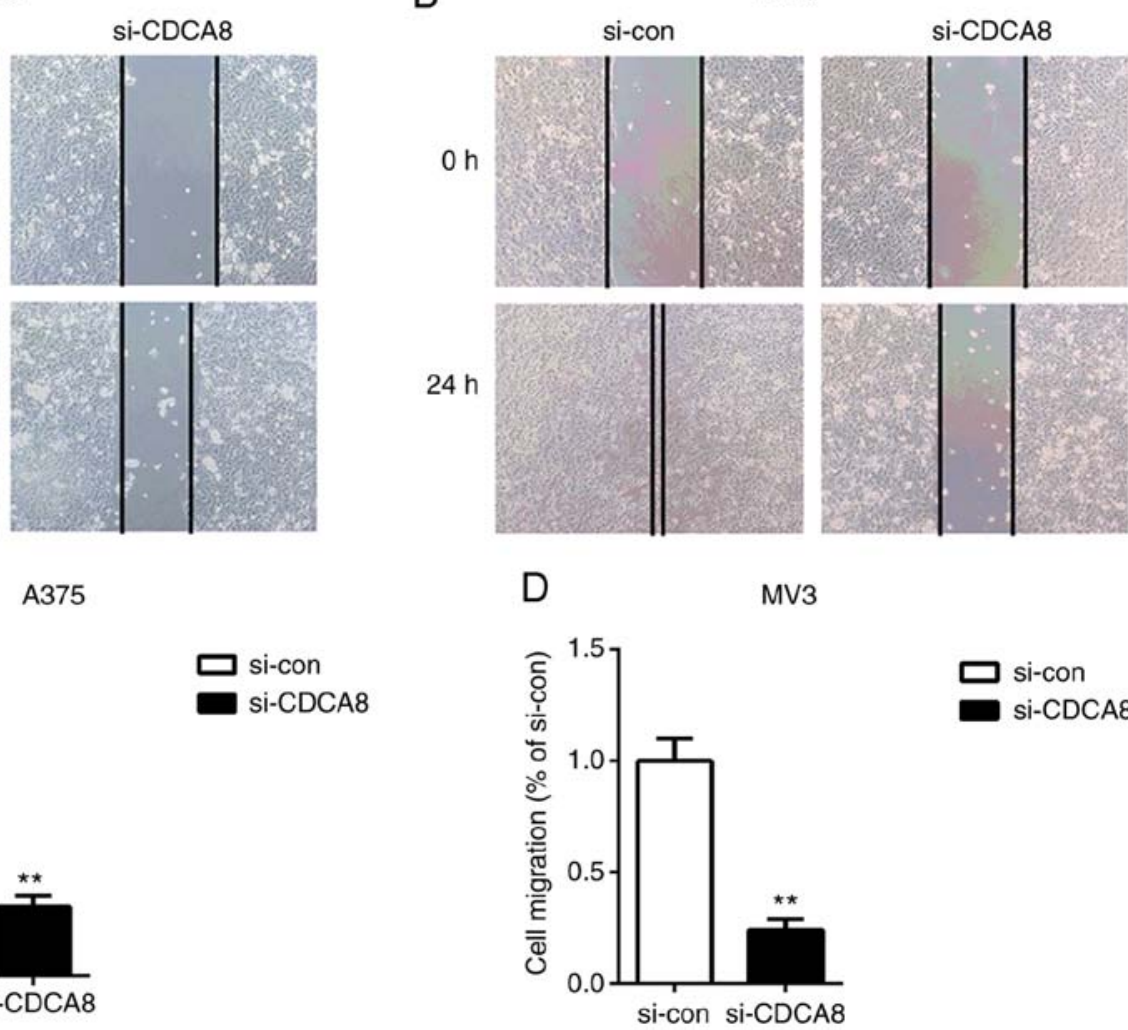

Figure 4. Effect of CDCA8 knockdown on A375 and MV3 cell migration. Representative microscopic images of wound-healing assays in (A) A375 and (B) MV3 cells following CDCA8 knockdown. Quantification of (C) A375 and (D) MV3 cells migration were measured. "* P $<0.01$ vs. si-con group. CDCA8, cell division cycle associated 8 ; si, small interfering. 
A

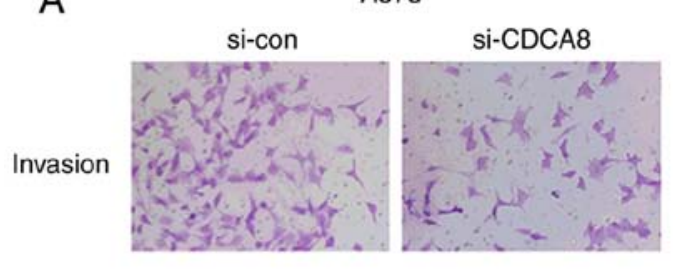

C

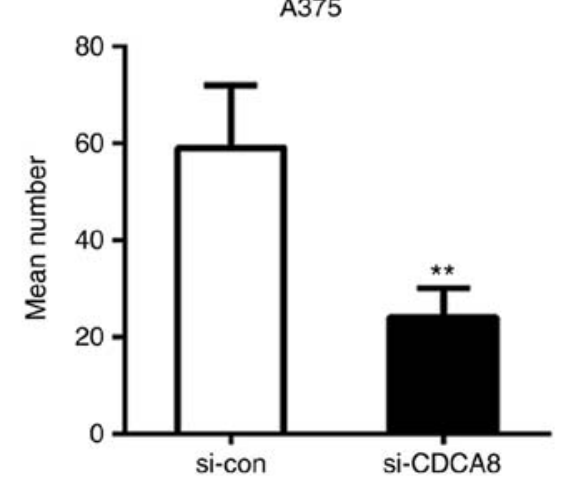

B

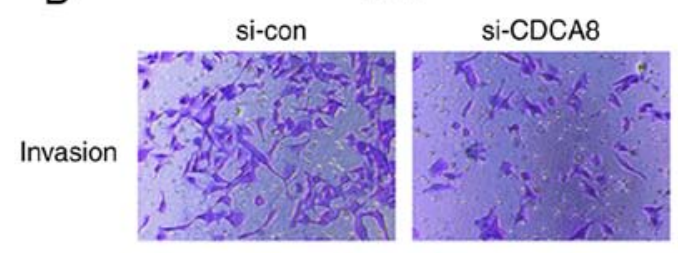

D

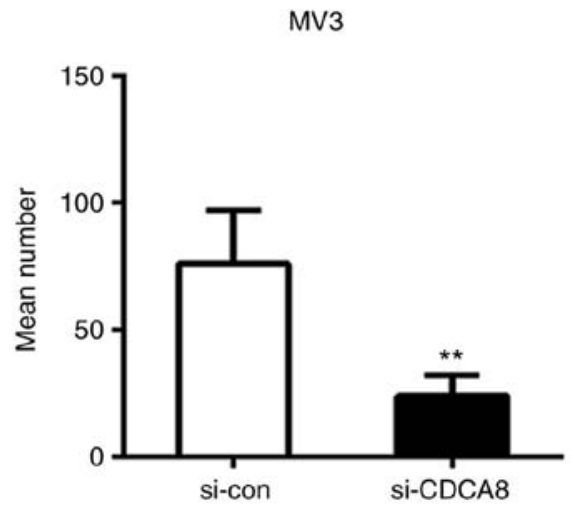

Figure 5. Effect of CDCA8 knockdown on A375 and MV3 cell invasion. Representative images of (A) A375 and (B) MV3 cells were showed in Matrigel assay. Quantification of (C) A375 and (D) MV3 cells invaded through Matrigel invasion chambers were measured. ${ }^{* *} \mathrm{P}<0.01$ vs. si-con group.
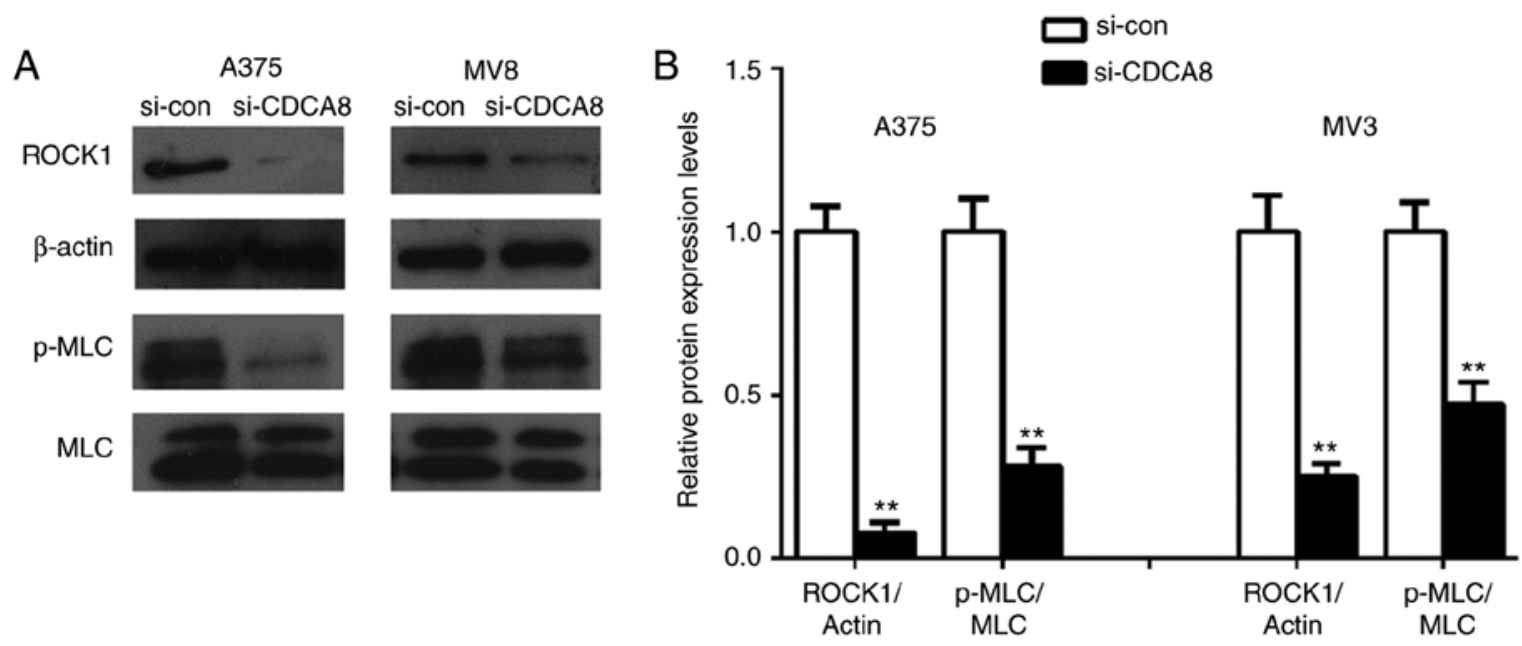

Figure 6. Effect of CDCA8 knockdown on ROCK signaling in A375 and MV3 cells. (A) Representative blot images and (B) quantification of ROCK1 and MLC expression levels, assessed by western blotting. ${ }^{* *} \mathrm{P}<0.01$ vs. si-con group. CDCA8, cell division cycle associated 8; ROCK, Rho-associated coiled-coil-containing protein kinase; MLC, myosin light chain; p-, phosphorylated; si, small interfering.

In fact, CDCA8 has been demonstrated to be indispensable for the growth of lung cancer cells, which was significantly inhibited by siRNA against CDCA8 $(7,19,20)$. In addition, proliferation of human embryonic stem cells (hESCs) was also reduced by CDCA8 knockdown (21). These studies are consistent with the present findings that CDCA8 knockdown inhibited the A375 and MV3 cell proliferation, migration and invasion. Furthermore, the present analysis revealed that the expression of CDCA8 was significantly associated with lymph node metastasis. Regional lymph node metastases constitute the most common mode of initial presentation with metastatic melanoma (22-24). The updated 2009 AJCC melanoma staging system reported that, in the absence of nodal metastases, patients with intralymphatic metastases have a 5 -year survival rate of only $69 \%$ (25), which may be one of the reasons CDCA8 affects the prognosis of cutaneous melanoma patients. In addition to being associated with poor prognosis in cutaneous melanoma patients, CDCA8 was also an independent prognostic factor, similar to the role of CDCA8 observed previously in breast cancer (12). These results indicate that CDCA8 has a crucial role in the progression of cutaneous melanoma.

In the present study, CDCA8 knockdown inhibited ROCK signaling in cutaneous melanoma cells. The ROCK signaling pathway is associated with cell proliferation and differentiation, apoptosis, cell cycle, cell polarity, the cytoskeleton and vasoconstriction $(13,14,26)$. The upstream protein $\mathrm{Rho}$ GTPase exists in all eukaryotic organisms and has roles in cell migration, movement, proliferation and differentiation (27). Activated RhoA binds directly to the C-terminus of ROCK 
and activates it. Activated ROCK phosphorylates myosin and its regulatory proteins to regulate changes of and contract the cytoskeleton (28). Therefore, ROCK signaling is important for cytoskeleton reorganization, cell migration, movement, contraction and proliferation. ROCK1, one of the two ROCK isoforms, is a major downstream effector of the small GTPase RhoA (29,30). ROCK1 has a role in cancer, especially cell motility, metastasis, and angiogenesis $(27,31,32)$. Furthermore, ROCK directly phosphorylates MLC, conducing to the actin-myosin force generation that is required for membrane blebbing (15), cell contraction $(26,33)$ and the formation of apoptotic bodies (29). The present results suggested that CDCA 8 knockdown reduced the expression levels of ROCK1 and phosphorylated MLC in A375 and MV3 cells. Taken together, these findings suggest that CDCA8 knockdown inhibited cutaneous melanoma cell proliferation and invasion potentially via the ROCK signaling pathway.

In summary, the present study used bioinformatics analysis and in vitro cell experiments to demonstrate that CDCA8 is a facilitator of the malignant progression of cutaneous melanoma cells via the ROCK pathway. Therefore, CDCA8 might be a promising prognostic factor and a potential therapeutic target for cutaneous melanoma patients. However, there are several limitations in this study. CDCA8 was suggested to be phosphorylated in vitro by aurora kinase B (AURKB), and co-transactivation of CDCA8 and AURKB was observed in several cancers. Consequently, the AURKB expression in cutaneous melanoma samples needs to be evaluated in synergy with CDCA8 in vitro. In addition, a decrease in ROCK1 expression may cause an increase in caspase-3/cleaved-caspase-8, which is important in cell apoptosis. Further studies to investigate the cell apoptosis following CDCA8 knockdown are necessary. Finally, further investigations with overexpression of CDCA8 and/or CDCA8 inhibitors are warranted in subsequent studies.

\section{Acknowledgements}

Not applicable.

\section{Funding}

No funding was received.

\section{Availability of data and materials}

The analyzed datasets generated during the study are available from the corresponding author on reasonable request.

\section{Authors' contributions}

CC, BT and DL conceived and designed the project. DL and WL provided administrative support. DQ, XJ, XQ collected data. XQ, LC and WD analyzed and interpreted the results. All authors contributed to writing, and all authors read and approved the final manuscript.

\section{Ethics approval and consent to participate}

Not applicable.

\section{Patient consent for publication}

Not applicable.

\section{Competing interests}

The authors declare that they have no competing interest

\section{References}

1. Matthews NH, Li WQ, Qureshi AA, Weinstock MA and Cho E: Epidemiology of melanoma. Environmental and molecular mutagenesis, 2017.

2. Goel N, Ward WH, Yu JQ and Farma JM: Short-term and long-term management of melanoma. In: Cutaneous melanoma: Etiology and therapy. Ward WH and Farma JM (eds.) Codon Publications, Brisbane (AU), 2017.

3. Joyce KM: Surgical management of melanoma. In: Cutaneous Melanoma: Etiology and therapy. Ward WH and Farma JM (eds.) Codon Publications, Brisbane (AU), 2017.

4. Norval M and Wright CY: The Epidemiology of cutaneous melanoma in the white and black African population groups in South Africa. In: Cutaneous melanoma: Etiology and therapy. Ward WH and Farma JM (eds.) Codon Publications, Brisbane (AU), 2017.

5. Rausch MP and Hastings KT: Immune checkpoint inhibitors in the treatment of melanoma: From basic science to clinical application. In: Cutaneous melanoma: Etiology and therapy. Ward WH and Farma JM (eds.) Codon Publications, Brisbane (AU), 2017.

6. G Lben K, Berberoglu U, Altinyollar H, Kinas V and Turanli S: Sentinel lymph node status affects long-term survival in patients with intermediate-thickness melanoma. J Cancer Res Ther 12: 840-844, 2016.

7. Phan NN, Wang CY, Li KL, Chen CF, Chiao CC, Yu HG, Huang PL and Lin YC: Distinct expression of CDCA3, CDCA5, and CDCA8 leads to shorter relapse free survival in breast cancer patient. Oncotarget 9: 6977-6992, 2018.

8. Gu Y, Lu L, Wu L, Chen H, Zhu W and He Y: Identification of prognostic genes in kidney renal clear cell carcinoma by RNAseq data analysis. Mol Med Rep 15: 1661-1667, 2017.

9. Yan H, Li Z, Shen Q, Wang Q, Tian J, Jiang Q and Gao L: Aberrant expression of cell cycle and material metabolism related genes contributes to hepatocellular carcinoma occurrence. Pathol Res Pract 213: 316-321, 2017.

10. Li S, Liu X, Liu T, Meng X, Yin X, Fang C, Huang D, Cao Y, Weng $\mathrm{H}$, Zeng $\mathrm{X}$ and Wang $\mathrm{X}$ : Identification of biomarkers correlated with the TNM staging and overall survival of patients with bladder cancer. Front Physiol 8: 947, 2017.

11. Sun L, Li J and Yan B: Gene expression profiling analysis of osteosarcoma cell lines. Mol Med Rep 12: 4266-4272, 2015.

12. Jiao DC, Lu ZD, Qiao JH, Yan M, Cui SD and Liu ZZ: Expression of CDCA8 correlates closely with FOXM1 in breast cancer: Public microarray data analysis and immunohistochemical study. Neoplasma 62: 464-469, 2015.

13. Çarçak N, Yavuz M, Eryiğit Karamahmutoğlu T, Kurt AH, Urhan Küçük M, Onat FY and Büyükafsar K: Suppressive effect of Rho-kinase inhibitors Y-27632 and fasudil on spike-and-wave discharges in genetic absence epilepsy rats from Strasbourg (GAERS). Naunyn-Schmiedebergs Arch Pharmacol 391: 1275-1283, 2018.

14. Cho SY, Sung CO, Chae J, Lee J, Na D, Kang W, Kang J, Min S, Lee A, Kwak E, et al: Alterations in the Rho pathway contribute to Epstein-Barr virus-induced lymphomagenesis in immunosuppressed environments. Blood 131: 1931-1941, 2018.

15. Dos Santos AA, López-Granero C, Farina M, Rocha JBT, Bowman AB and Aschner M: Oxidative stress, caspase-3 activation and cleavage of ROCK-1 play an essential role in $\mathrm{MeHg}$-induced cell death in primary astroglial cells. Food Chem Toxicol 113: 328-336, 2018.

16. Honjo $M$ and Tanihara H: Impact of the clinical use of ROCK inhibitor on the pathogenesis and treatment of glaucoma. Jap J Ophthalmol 62: 109-126, 2018.

17. Li N, Chen J, Zhao J and Wang T: MicroRNA-3188 targets ETS-domain protein 4 and participates in RhoA/ROCK pathway to regulate the development of atherosclerosis. Pharmazie 72: 687-693, 2017. 
18. Livak KJ and Schmittgen TD: Analysis of relative gene expression data using real-time quantitative PCR and the 2(-Delta Delta C(T)) method. Methods 25: 402-408, 2001.

19. Dai C, Miao CX, Xu XM, Liu LJ, Gu YF, Zhou D, Chen LS, Lin G and Lu GX: Transcriptional activation of human CDCA8 gene regulated by transcription factor NF-Y in embryonic stem cells and cancer cells. J Biol Chem 290: 22423-22434, 2015.

20. Papini D, Langemeyer L, Abad MA, Kerr A, Samejima I, Eyers PA, Jeyaprakash AA, Higgins JM, Barr FA and Earnshaw WC: TD-60 links RalA GTPase function to the CPC in mitosis. Nat Commun 6: 7678, 2015.

21. Marko NF, Weil RJ, Schroeder JL, Lang FF, Suki D and Sawaya RE: Extent of resection of glioblastoma revisited: Personalized survival modeling facilitates more accurate survival prediction and supports a maximum-safe-resection approach to surgery. J Clin Oncol Mar 32: 774-82. 2014.

22. Huang SK and Hoon DS: Liquid biopsy utility for the surveillance of cutaneous malignant melanoma patients. Mol Oncol 10 : 450-463, 2016

23. Pan Y, Haydon AM, McLean CA, McDonald PB and Kelly JW: Prognosis associated with cutaneous melanoma metastases. Australas J Dermatol 56: 25-28, 2015.

24. Jaber DF, Jallad MN and Abdelnoor AM: The effect of ciprofloxacin on the growth of B16F10 melanoma cells. J Cancer Res Ther 13: 956-960, 2017.

25. Weiss SA, Hanniford D, Hernando E and Osman I: Revisiting determinants of prognosis in cutanous melanoma. Cancer 121 4108-4123, 2015.

26. McCarthy CG, Wenceslau CF, Ogbi S, Szasz T and Webb RC: Toll-like receptor 9-dependent AMPKalpha activation occurs via TAK1 and contributes to RhoA/ROCK signaling and actin polymerization in vascular smooth muscle cells. J Pharmacol Exp Ther 365: 60-71, 2018.

27. Takaoka M, Ito S, Miki Y and Nakanishi A: FKBP51 regulates cell motility and invasion via RhoA signaling. Cancer Sci 108: 380-389, 2017.
28. Pich C, Teiti I, Sarrabayrouse G, Gallardo F, Gence R and Tilkin-Mariame AF: Melanoma expressed-CD70 is regulated by RhoA and MAPK pathways without affecting vemurafenib treatment activity. PLoS One 11: e0148095, 2016.

29. Sahin L, Cevik OS, Koyuncu DD and Buyukafsar K: Role of rho-kinase (ROCK) in tonic but not phasic contraction in the frog stomach smooth muscle. Life Sci 198: 46-55, 2018.

30. Zeng Y, Xie H, Qiao Y, Wang J, Zhu X, He G, Li Y, Ren X, Wang F, Liang L and Ding Y: Formin-like2 regulates Rho/ROCK pathway to promote actin assembly and cell invasion of colorectal cancer. Cancer Sci 106: 1385-1393, 2015.

31. Shen K, Wang Y, Zhang Y, Zhou H, Song Y, Cao Z, Kou J and Yu B: Cocktail of four active components derived from Sheng Mai San inhibits hydrogen peroxide-induced PC12 cell apoptosis linked with the caspase-3/ROCK1/MLC pathway. Rejuvenation Res 18: 517-527, 2015.

32. Voorneveld PW, Kodach LL, Jacobs RJ, Liv N, Zonnevylle AC, Hoogenboom JP, Biemond I, Verspaget HW, Hommes DW, de Rooij K, et al: Loss of SMAD4 alters BMP signaling to promote colorectal cancer cell metastasis via activation of Rho and ROCK. Gastroenterology 147: 196-208, 2014.

33. Mu D, Zhou G, Li J, Su B and Guo H: Ursolic acid activates the apoptosis of prostate cancer via ROCK/PTEN mediated mitochondrial translocation of cofilin-1. Oncol Lett 15: 3202-3206, 2018.

(i) $(-)$ This work is licensed under a Creative Commons Attribution-NonCommercial-NoDerivatives 4.0 International (CC BY-NC-ND 4.0) License. 